\title{
SHORT-TERM TRAINING PROGRAM FOR THE PREPARATION PERIOD IN THE ENDURANCE DISCIPLINE OF EQUESTRIAN SPORT
}

\author{
Ruzha Nedkova-Ivanova, Yuri Valev \\ National Sports Academy “Vassil Levski”, Sofia, Bulgaria
}

ORCID (1D

Ruzha Nedkova-Ivanova https://orcid.org/0000-0002-6051-8229

Yuri Valev https://orcid.org/0000-0002-3238-6089

\begin{abstract}
The competitive pairs of horse and rider in the endurance discipline of equestrian sport in Bulgaria have ranked, in the past several years, amongst the elite contestants in Europe and the world, which has necessitated deeper studies in the areas of training methods and the ways of achieving high sport results. Therefore, this study is focused on 6 Bulgarian horses (Arabian horse and Shagya, Table 1) that are preparing for European and World championships. They were trained together under the same conditions (climate, time zone, tarrain, speed) by riders with the necessary qualifications and experience. Seven training rides were performed, and the pulse was measured at the moment of the highest load, as it is the most indicative of the horse's level of effort. By studying the pulse of horses during a training session, the research aimed to determine the efficacy of the short-term training program in the prep season. The results showed that 2 to 4 minutes after coming to a full stop, regardless of the terrain, speed (in this research between $5.2 \mathrm{~km} / \mathrm{h}$ and $22.5 \mathrm{~km} / \mathrm{h}$ ) or distance travelled by the horses, their pulse varied between 36 and 99 bpm (beats per minute) and they improved their physical condition and increased their stamina without this leading to trauma or more serious injuries, which is a main priority in the equestrian sport and allows for the successful completion of every race. In the long run, such a training methodology will allow the horses to be trained and ready to race at any time. Monitoring the heart rate and keeping it within the studied limits showed that this was the optimal option for a training regime for the six examined horses. In the situation with the COVID-19 pandemic, this is a possible solution for maintaining athletic fitness in endurance horses.
\end{abstract}

Key words: horse, endurance, training, preparation period, pulse.

\section{INTRODUCTION}

The endurance event in equestrian sport is a challenge to the rider in terms of his capabilities to lead the horse in a precautious manner on the endurance track. The route is designed to test the stamina and fitness of the rider and the horse, respectively, against the marked tour, distance, terrain, climate and clock without compromising the well-being of the horse (FEI, 2020).
Endurance sport's highest concept is "fit to continue". This term should have meaning for the endurance riders "that goes far beyond just the sense of the "race" itself" (Loving, 1997).

There are a lot of studies about the physiology of sport horses in competitions or in training in the different equestrian disciplines, including: racing (Vermeulen and Evans, 2006), trotters (Fortier et al., 2015), polo (Ferraz et al., 2010), endurance riding (Fraipont 
et al., 2012) and western sports (Casella et al., 2015). Endurance riding is not an Olympic discipline, but currently the most popular in Bulgaria with the high achievements of the endurance competitors. The country has already high quailified riders for the highestlevel endurance races - European and World Championships and the World Equestrian Games (Valev, 2020). The European Championships are held in even-numbered years, the World Championships in odd-numbered years, and the World Equestrian Games are held every 4 years (FEI, 2020). All championships in the endurance discipline are held at a distance of $160 \mathrm{~km}$ over one day and with an average speed of over $12 \mathrm{~km} / \mathrm{h}$ for each loop of the competition. The loops are 6 , divided into distances between 40 and $20 \mathrm{~km}$ (FEI, 2020). The races organized in this way allow couples competeing in the endurance discipline to take part every year in competitions of the highest category, which require appropriate training, because such competitions are attended by elite horses and riders who have met the necessary qualifications and have shown the best achievements in current racing year or the previous one. Since the horse has a leading role in the horse-rider couple, this research was based on its functional indicators and its overall physical condition.

Endurance horses undergo severe stress during the course of a competitive ride. These horses are trained and conditioned to perform over long distances at moderate speeds. When conditioning a horse for long distance competitions, the training program must be designed and monitored to match the specific exercise type and intensity of competitive endurance riding (Linder et al., 2006).

To follow the progress of the endurance horse, it is important to check its ability to perform the required work regulary without physical or metabolic hazard. For this aim, riders and trainers in Endurance use cardiotachometer or heart rate monitor to check the heart rate during and after a ride. This helps to understand how well horses cope with the exircise stress. Ideally, horses recover their pulse to less than 60-64 bpm within 5-10 minutes following an aerobic workout (Loving, 1997).

The relationship of the heart rate and the performance of the horse were described by Steel in the 1960's (cited in Steward, 1981) and are still important makers for the fitness and health of the sports horse, especially in endurance. Only more recently have training programmes evolved to use more quantitative assessments of horses' athletic improvement. Heart rate, oxygen consumption and lactate accumulation with exercise are quantitative factors that can evaluate progress (Persson 1983; Pringle et al. 1999). The running speed-heart rate relationship is easily measured and reproducible and can be applied under field conditions (Couroucé et al., 2000). On the other hand, heart rate can be influenced by external factors such as anxiety or excitement and can fluctuate significantly at lower working intensities. Even with its limitations, heart rate is still used extensively as a fitness indicator (Trilk et al., 2002). Oxygen consumption is a metabolic indicator of fitness and athletic improvement. Substrate utilisation and energy expenditure can be determined through measuring oxygen consumption (Seeherman and Morris, 1990), but it is generally available only for clinical trials and is impractical for field use (Trilk et al., 2002). Blood lactate measurements are also used regularly to assess the level of horse's fitness and there is a lot of research, which shows the connection to the condition of the horse (Mohr et al., 1999). Taking blood from horses during training is also a complicated process demanding a veterinarian and more preparation.

Bulgaria has twice successfully ranked 
among the best teams in the world and Europe so there is a resource of horses and riders at the highest level. This study was based on the heart rate of Bulgarian elite horses (Arabian horse and Shagya, Table 1) as one of the main information indicators for the training of the horse, along with blood lactate (Castejon-Riber et al., 2017). The presented training program and its results will enable all elite athletes and coaches in this discipline to compare and upgrade their work in order to improve sports results.

\section{PURPOSE OF THE STUDY}

This study aims to provide a developed short-term training program for elite horses in the discipline of endurance in equestrian sports, which refers to the preparatory (initial) period of training preceding the racing season. This program aims to gradually improve sports conditions of the horses, preparing them for loading during the race at distances of $120 \mathrm{~km}$ to $160 \mathrm{~km}$ per day at speeds above $12 \mathrm{~km} / \mathrm{h}$ for each stage of the race, protecting them from traumas, injuries that may be the result of both insufficient training or overtraining.

The training is fully adapted to the age of the horses, their racing level so far, as well as their physical condition at any time during the training. The highest principle in equestrian sport is the preservation of the welfare of horses (Robert, 2002), whether in training, competition or during rest, so the applied program should be guided by it.

The specified short-term training program will implement a study that has not yet been conducted in Bulgaria on a similar scale. The results will give information about the club for which the six horses compete and whether their training methodology is correct or needs improvements and changes. Bulgarian Endurance riders are quite successful nationally and internationally, but these achievements are not based on a clearly elaborated methodology that is accessible to everyone, so such a study allows for a wider range of stakeholders to learn about scientifically developed methods for training horses for endurance discipline.

\section{MAIN HYPOTHESIS}

The short-term training program for elite horses breed types (Arabian horse and Shagya, Table 1) in the endurance discipline should be fully adapted to their physical condition. We believe that a training in which horses are ridden the longest time (over $70 \%$ of training) at a heart rate between 64 and $150 \mathrm{bpm}$ and after stopping for 2 to 4 minutes their heart rate is between 36 and 99 bpm will improve their racing capabilities without causing trauma or more serious injuries and will fully prepare them for top-ranked races.

\section{METHODS}

The research was done with 6 horse-rider racing pairs and presents the results from the measurement of the heart rate of the horses as a key indicator of the horse training in seven training rides with different loads. The heart rate measurements were made during or at the end of the training, which took place on different terrain - flat, down and uphils, field and mountains, and were of different duration - between 1 and 2 hours, and speed between $5.2 \mathrm{~km} / \mathrm{h}$ and $22.5 \mathrm{~km} / \mathrm{h}$ (Figure 2). The racing couples performed the training program as set in Tabl. 3 - week model for two and a half months. Pulse was measured 42 times in 7 rides of 6 horses. All six pairs are elite competitors successfully ranked at international competitions with the rank of CEI $2 *(120-139 \mathrm{~km} /$ day) and CEI $3 *$ (140-160 km/day) and preparing to participate in the World Championship (160 km/day, $3^{*}$ Championship) in the discipline endurance. The horses are aged between 9 and 13 years, and the competitors are aged between 27 and 54 years. 
According to the international regulations of FEI (International Equestrian Federation) age condition gives them the right to participate in competitions, men's category CEI 2*, CEI 3* and Championship, after successfully passing all mandatory qualifications.

SPSS statistics software and polarflow ap- plication were used in the processing of the results.

\section{Subjects}

The participants in the study - horses and riders and their specifics are shown in Tables 1 and 2.

Table 1. Breed, age and gender of horses participating in the study

\begin{tabular}{cccc}
\hline Horse & Breed & Age (years) & Sex \\
\hline 1 & Arabian horse & 13 & gelding \\
2 & Shagya & 11 & mare \\
3 & Arabian horse & 12 & mare \\
4 & Arabian horse & 12 & mare \\
5 & Arabian horse & 11 & mare \\
6 & Shagya & 9 & gelding \\
\hline
\end{tabular}

Table 2. Age, gender and level of completed competitions of the riders of six horses included in the experiment.

\begin{tabular}{ccccc}
\hline Rider & Age & Sex & $\begin{array}{c}\text { Level 120 Km (number of } \\
\text { successful competitions) }\end{array}$ & $\begin{array}{c}\text { Level 160 кm (number of } \\
\text { successful competitions) }\end{array}$ \\
\hline 1 & 27 & man & 9 & 5 \\
2 & 51 & man & 4 & 3 \\
3 & 39 & woman & 9 & 1 \\
4 & 37 & woman & 4 & 0 \\
5 & 40 & woman & 3 & 1 \\
6 & 54 & man & 10 & 4 \\
\hline
\end{tabular}

All the 6 riders had successfully completed races at a distance of $120 \mathrm{~km}$. Five of them had successfully completed competitions at 160 $\mathrm{km}$. The riders were prepared for competitions at a distance of 120 and $160 \mathrm{~km}$ and met the training requirements and qualifications of the six horses in the experiment.

\section{Materials}

A Polar Ignite watch, a Polar belt heart rate monitor, a Polar Equine Healthcheck, a handheld heart rate monitor, the Polar Flow application and some information from www. flow.polar.com, were used for conducting the study as usually used in other studies (Lindner et al., 2020). Polar belt heart rate monitor and
Polar Equine Healthcheck were attached to the thorax of the horse as described in the manufacturer's instructions. Some gel was used for full contact between skin and device.

\section{Duration of the study}

The study started on January 1, 2020 and ended on March 13, 2020 along the following monthlyplan(mesocycle) underthe supervision of the coach and the team's veterinarian:

- LSD (Long Slow Distance) - 3-4 times monthly;

- Basic training - 6-8 times monthly;

- Manege training-3-5 times monthly;

- Conditioning training - 4-6 times monthly;

- Full rest in the paddock - 4-8 days monthly; 


\section{EXPLANATION OF TERMS:}

1. Basic training - this is the degree of work with the horse that does not stress it. It helps building its physical condition properly.

2. Manege training - these are the days for work when the horse rests from stress. The workout can include 20 minutes work with a horse walker - walking and trotting or manege work from the ground and on the saddle with certain exercises.

3. Conditionning training - a work with the horse, which allows it to become strong and tough enough to participate in endurance competitions without danger for its health.

4. Heavy loading/canter - this is a load for the horse, to which it is generally not accustomed and requires more energy. It is typical for this type of training that the horse's heart rate is higher than the usual within 20 minutes. This means that the horse is loaded to a sufficiently high degree and reaches a level of stress.

5. Rest day - normally this is the day after a heavy load training, and sometimes these days are 2 or more depending on the trainer's judgement.

The weekly training program (microcycle) is presented in Table 3. (Valev, Nedkova-Ivanova, 2018).

Table 3. Weekly training programm

\begin{tabular}{ll}
\hline Day of the week & Training program \\
\hline Monday & Rest \\
Tuesday & Basic training with up-riding $(1-2 \mathrm{~h})$ \\
Wednesday & Manege training \\
Thirsday & Conditioning training $(1-2 \mathrm{~h})$ \\
Friday & Rest \\
Saturday & Cross country basic training $(1-3 \mathrm{~h})$ \\
Sunday & (canter)/conditioning training \\
\hline
\end{tabular}

Table 4. Pulse'rates during different gaits

\begin{tabular}{cccc}
\hline Movement & Pulse (beats/minute) & Loading level & Energetic system \\
\hline Standing & $25-60$ & very low & Aerobic \\
Walk & $50-90$ & very low & Aerobic \\
Trot & $80-150$ & low & Aerobic \\
Canter & $120-160$ & moderate & Mostly Aerobic \\
Gallop & $150-200$ & high & Mixed Aerobic and anaerobic \\
Carriere & $200-230$ & very high & Highly anaerobic, partly aerobic \\
\hline
\end{tabular}

It is important for endurance horses to be ridden at such a pace that they do not reach a heart rate higher than 100-150 bpm (Table 4). Under heavy load/canter, the pulse can reach $220 \mathrm{bpm}$ depending on the type of terrain and speed, but this state should last a maximum of 20 minutes (Evans, 2000). Even though en- durance riding is classified as a prolonged aerobic exercise (Siqueira et al., 2014), the high oxygen demands over a longer period of time result in an increased reactive oxygen species (ROS) formed by 1 to $2 \%$ of the oxygen that is not completely reduced into carbon dioxide and water (Sjodin et al., 1990). 


\section{RESULTS AND ANALYSIS}

The obtained results showed that these six horses's pulse frequencies varied between 47 and $202 \mathrm{bpm}$, and their average frequency was $103 \mathrm{bpm}$, which is shown in Figure 1. The condition to not be ridden when the horse'pulse rate was above $200 \mathrm{bpm}$ was respected for not more than 20 minutes. The data showed that horses were ridden with a heart rate between 171 and $202 \mathrm{bpm}$ within 4 minutes and 39 seconds. The speed of the horses in the training seasons was between $5.2 \mathrm{~km} / \mathrm{h}$ and $22.5 \mathrm{~km} / \mathrm{h}$, shown in Figure 2.

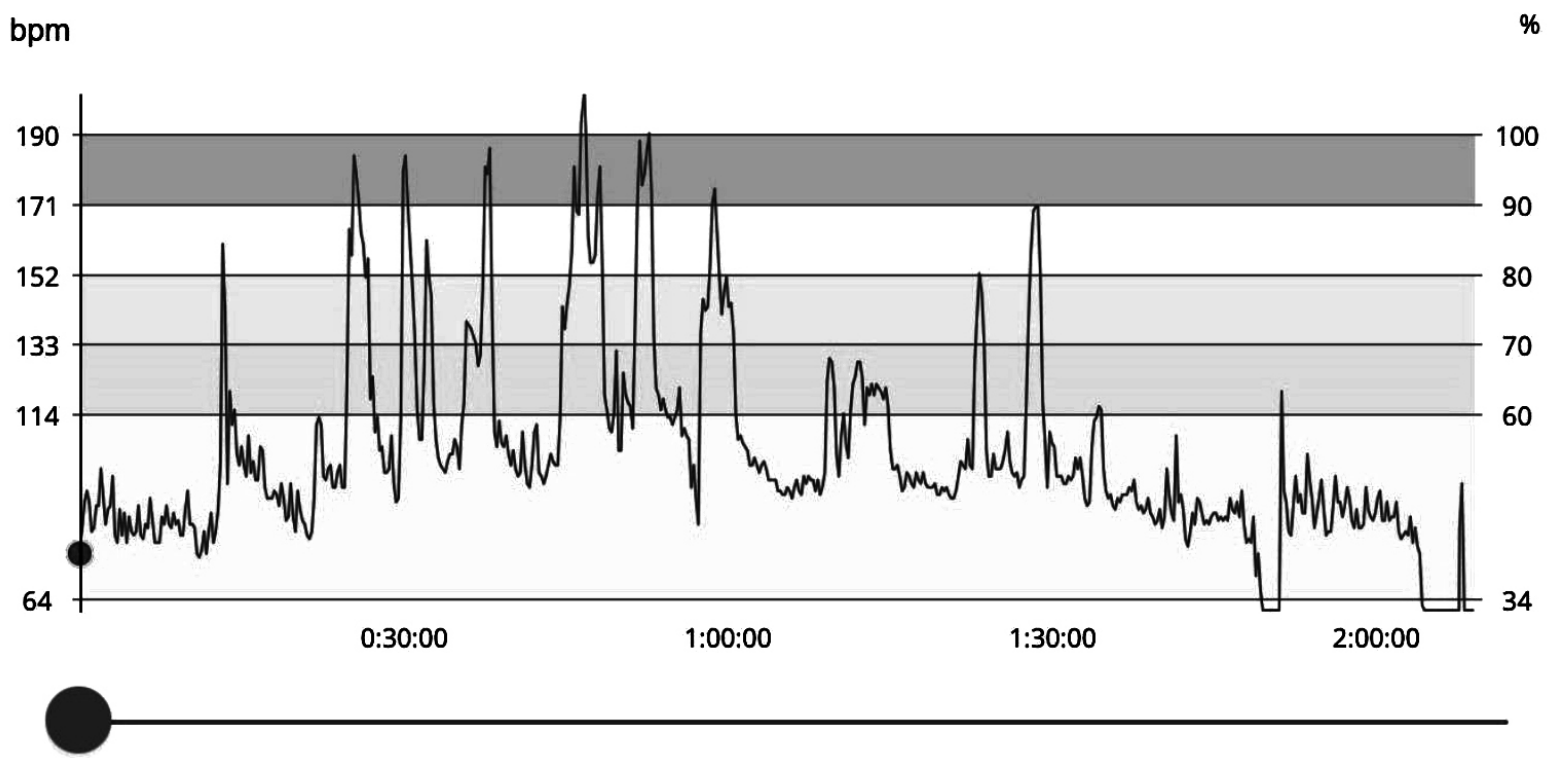

Figure 1. Typical heart rate distribution during endurance horse training (the graph was taken from the Polar Flow application, which was prepared from Polar Ignite watch data after training).

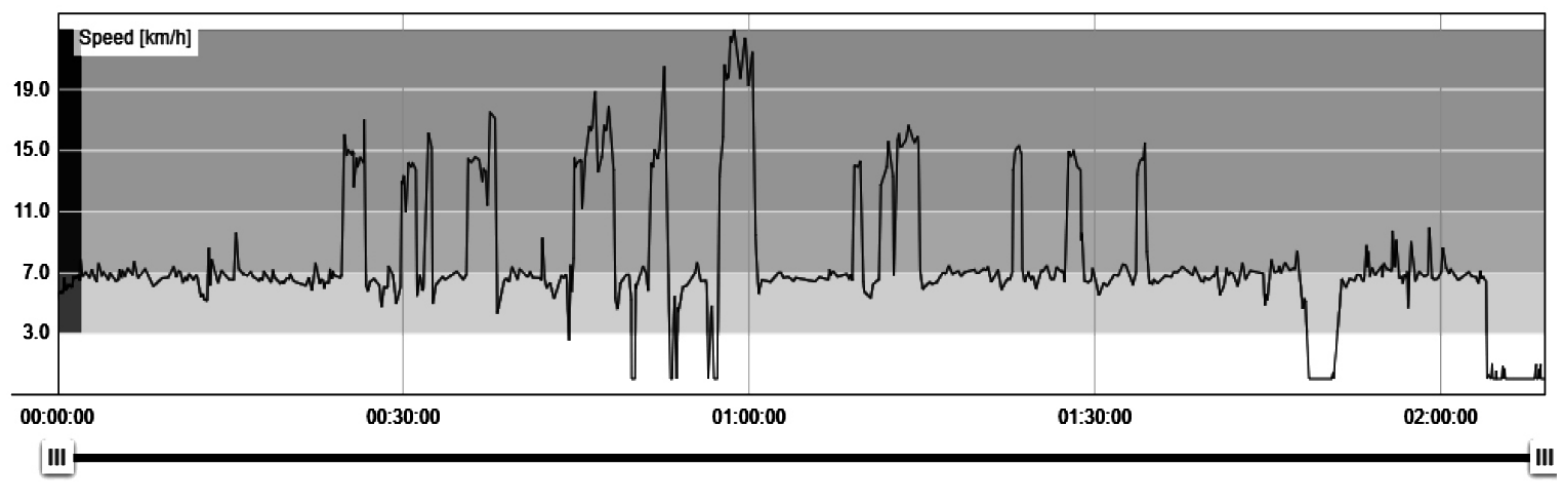

Figure 2. Speed limits during the training sessions (the graph was taken from the Polar Flow application, which was prepared from Polar Ignite watch data after training).

Despite the differences in training grounds and distances, pulse indicators vary within the limits of the permissible conditioning load during the preparation period, namely between
36 and $99 \mathrm{bpm}$, measured from 2 to 4 minutes, with speed limits from $5.2 \mathrm{~km} / \mathrm{h}$ to maximum $22.5 \mathrm{~km} / \mathrm{h}$ (Figure 2).

After all heart rate measurements, the follo- 
wing summaries and conclusions can be made, 30]; The horses' heart rate varied between 36 (see Table 5 and Table 6): Horses maintained a and 99 beats per minute, which shows that the relatively constant heart rate during their seven training methodology was applied correctly training sessions. The coefficient of variation and gave its positive results on the physical belongs to the interval $20-30 \% \mathrm{~V} \% \in[20-$ condition of the horses.

Table 5. Minimum and maximum heart rate of the six horses participating in the seven training rides.

\begin{tabular}{|c|c|c|c|c|c|c|c|c|}
\hline & \multirow[b]{2}{*}{$\mathbf{N}$} & \multirow[b]{2}{*}{ Mean } & \multirow{2}{*}{$\begin{array}{l}\text { Std. De- } \\
\text { viation }\end{array}$} & \multirow{2}{*}{$\begin{array}{l}\text { Std. } \\
\text { Error }\end{array}$} & \multicolumn{2}{|c|}{ 95\% Confidence Interval for Mean } & \multirow{2}{*}{ Minimum } & \multirow{2}{*}{ Maximum } \\
\hline & & & & & Lower Bound & Upper Bound & & \\
\hline 1 & 7 & 71.71 & 15.607 & 5.899 & 57.28 & 86.15 & 44 & 88 \\
\hline 2 & 7 & 75.00 & 21.894 & 8.275 & 54.75 & 95.25 & 40 & 99 \\
\hline 3 & 7 & 63.14 & 16.517 & 6.243 & 47.87 & 78.42 & 36 & 87 \\
\hline 4 & 7 & 67.00 & 17.786 & 6.722 & 50.55 & 83.45 & 41 & 89 \\
\hline 5 & 7 & 70.14 & 19.386 & 7.327 & 52.21 & 88.07 & 39 & 95 \\
\hline 6 & 7 & 66.29 & 17.604 & 6.654 & 50.00 & 82.57 & 38 & 89 \\
\hline Total & 42 & 68.88 & 17.543 & 2.707 & 63.41 & 74.35 & 36 & 99 \\
\hline
\end{tabular}

$* \mathrm{~N}=$ number of rides

Table 6. Pulse rate variation factor for the seven rides.

\begin{tabular}{cccc}
\hline Number & Mean & Std. Deviation & Variance coefficient \\
\hline 1 & 71.71 & 15.607 & $21.76 \%$ \\
2 & 75 & 21.894 & $29.19 \%$ \\
3 & 63.14 & 16.517 & $26.16 \%$ \\
4 & 67 & 17.786 & $26.55 \%$ \\
5 & 70.14 & 19.386 & $27.64 \%$ \\
6 & 66.29 & 17.604 & $26.56 \%$ \\
7 & 68.88 & 17.543 & $25.47 \%$ \\
\hline
\end{tabular}

It can be seen that at significance level $\alpha=$ .05 the result from the test for homogeneity of scattering (Levene Test) shows that there was no significant difference between scattering in heart rate values in the studied horses ( $\mathrm{Sig}$ $=.904>.05)$ The conclusion is confirmed by the results from the analysis of the variance
(Table 8). With a 95\% guarantee probability $(\alpha=.05)$ we can say that the pulse rate of the studied horses was constant $(\mathrm{Sig}=.859>$ $.05)$. Perceiving the pulse rate as a measure of training of the studied horses, the conclusion is that they had the same degree of training and preparation.

Table 7. Levene test for the difference between scattering in heart rate values.

\begin{tabular}{cccc}
\hline Levene Statistic & df1 & df2 & Sig. \\
\hline .310 & 5 & 36 & .904 \\
\hline
\end{tabular}

Table 8. Anova test for the constant pulse of the six horses.

\begin{tabular}{lcrccc}
\hline & Sum of Squares & df & Mean Square & F & Sig. \\
\hline Between Groups & 631.833 & 5 & 126.367 & .380 & .859 \\
Within Groups & 11986.571 & 36 & 332.960 & & \\
Total & 12618.405 & 41 & & & \\
\hline
\end{tabular}


In table 9 we can see the six horses' heart rides, clearly showing that they varied between rates measured during their seven training min $36 \mathrm{bpm}$ and max $99 \mathrm{bpm}$.

Table 9. Difference between the minimum and maximum heart rate of the six horses and the average heart rate.

\begin{tabular}{ccccccc}
\hline \multirow{2}{*}{ Horse pulse } & N & Range & Minimum & Maximum & Mean & Std. Deviation \\
\cline { 2 - 7 } & Statistic & Statistic & Statistic & Statistic & Statistic & Statistic \\
\hline 1 & 7 & 44 & 44 & 88 & 71.71 & 15.607 \\
2 & 7 & 59 & 40 & 99 & 75.00 & 21.894 \\
3 & 7 & 51 & 36 & 87 & 63.14 & 16.517 \\
4 & 7 & 48 & 41 & 89 & 67.00 & 17.786 \\
5 & 7 & 56 & 39 & 95 & 70.14 & 19.386 \\
6 & 7 & 51 & 38 & 89 & 66.29 & 17.604 \\
\hline
\end{tabular}

$* \mathrm{~N}=$ number of rides

According to table 10 and the Kolmogorov- six horses were normally distributed, at a Smirnoff test, the heart rate values for the significance level $\alpha=.05(\operatorname{Sig}=.978>.05)$.

Table 10. Distribution of values

\begin{tabular}{|c|c|c|c|c|c|c|c|}
\hline & & $\begin{array}{l}\text { Horse } \\
1 \text { pulse }\end{array}$ & $\begin{array}{l}\text { Horse } \\
2 \text { pulse }\end{array}$ & $\begin{array}{l}\text { Horse } \\
3 \text { pulse }\end{array}$ & $\begin{array}{l}\text { Horse } \\
4 \text { pulse }\end{array}$ & $\begin{array}{l}\text { Horse } \\
5 \text { pulse }\end{array}$ & $\begin{array}{l}\text { Horse } \\
6 \text { pulse }\end{array}$ \\
\hline $\mathrm{N}$ & & 7. & 7. & 7. & 7. & 7. & 7. \\
\hline \multirow[t]{2}{*}{ Normal Parameters ${ }^{a, b}$} & Mean & 71.71 & 75.00 & 63.14 & 67.00 & 70.14 & 66.29 \\
\hline & Std. Deviation & 15.607 & 21.894 & 16.517 & 17.786 & 19.386 & 17.604 \\
\hline \multirow{3}{*}{$\begin{array}{l}\text { Most Extreme } \\
\text { Differences }\end{array}$} & Absolute & .180 & .162 & .187 & .160 & .175 & .198 \\
\hline & Positiv & .148 & .136 & .153 & .160 & .128 & .198 \\
\hline & Negative & -.180 & -.162 & -.187 & -.143 & -.175 & -.185 \\
\hline \multirow{2}{*}{\multicolumn{2}{|c|}{$\begin{array}{l}\text { Kolmogorov-Smirnov Z } \\
\text { Asymn. Sig (2-tailed) }\end{array}$}} & .475 & .428 & .494 & .424 & .463 & .524 \\
\hline & & .978 & .993 & .968 & .994 & .983 & .946 \\
\hline
\end{tabular}

The measurements showed that the average heart rate of the examined horses ranged from 63.14 to 75 beats per minute. The minimum measured heart rate for horse 3 was $36 \mathrm{bpm}$, and the maximum for horse $2-99 \mathrm{bpm}$.

The effects of exercise speed and duration on heart rate recovery were previously described (Hall et al., 1976). In this research horses were ridden for training and with speed between $5.2 \mathrm{~km} / \mathrm{h}$ and $22.5 \mathrm{~km} / \mathrm{h}$. This was the limit, set by the trainer and veterinarian, so the horses were not trained under stress for a long time. In the long term, the body systems of the horse adapt to the stress of exercise. This helps for producing more energy and for strengthen- ing the supporting structures. Too much stress between workouts leads to overloading injuries (Clayton, Science, 1992).

There are a lot of studies showing the relationship between heartrate and physicaly condition of sports horses. Few are the studies especially carried out with endurance sport horses, which are based more on competition level (Bennet, Parkin, 2018), than on training, so more research had to be done in this direction. It was important to design a methodology of training precisely oriented to Bulgarian endurance horses' conditions. Another study followed a standardized stepwise exersice test for endurance horses and the connection 
to heart rate, but there were different types of horses and at a different level (Sloet van Oldruitenborgh-Oosterbaan et al., 1987). Such studies were carried out in the 80's (Asheim et al., 1970), the technical materials for measuring the heartrate has changed, the speeds of the horses have changed, FEI rules have changed many times (https://inside.fei.org/ node/3835/), so the information is not as relevant as desired any more. New surveys about heartrate of high-level endurance horses in training are needed. There are not such studies in Bulgaria or such methodologies of training. Therefore, this study is of great importance for development of endurance riding discipline in the country.

\section{Limitations and future research direc- tions}

As the implementation of the study coincided with the beginning of the COVID-19 pandemic in Bulgaria, the period of preparation for upcoming competitions was extended indefinitely. The horses were trained according to the method described above; only the heavy load/canter was reduced and replaced with conditioning training (with a horse walker on walking and trotting programs) because training was prohibited. In this program the horses remained healthy, motivated, in very good shape and with a desire to work, which was evident in the resumption of training on May 4, 2020. When working in this direction at the start of the racing season, these 6 horses could acquire cantering and could be in top form on the day of the race two weeks before announced competition. Given the unexpected situation, the fact that the horses kept their heart rate constant and were in good general physical condition, gives the reason to believe that such a developed methodology is not only suitable for short-term training program, but also at such moments that require a radical change in preparation plans and strategies.

In order to implement the presented methodology among a wider range of stakeholders and to improve the shown results this test should be supplemented and continued with tests during the active racing period and immediately before the CEI $2 *$ and CEI $3 *$ races, measuring the heart rate during and immediately after a longer canter between hour and hour and half without a break. Some seminars and online trainings can be organized, paying special attention to the topic of training horses in Endurance discipline and presenting the final results from this experiment. The promotion of using technical equipment and the constant monitoring of the horses ${ }^{6}$ heart rate during training are a main helper in detecting problems related to the physical condition of the horses.

\section{CONCLUSION}

In this study, it was concluded that by regularly monitoring the heart rate of horses, it can be judged whether these horses feel equally well and are equally trained in the short-term training program. The results of the measurements showed that the six horses accepted the load under which they are subjected positively, and their heart rate remained within acceptable limits.

\section{REFERENCES}

Asheim A, Knudsen O, Lindholm A, Rülcker C, Saltin B. (1970). Heart rates and blood lactate concentrations of standardbred horses during training and racing. $\mathrm{J} \mathrm{Am} \mathrm{Vet} \mathrm{Med} \mathrm{As-}$ soc. 157 , pp. 304-312.

Bennet, E. D. and Parkin, T. D. H. (2018). Fédération Equestre Internationale (FEI) endurance events: Riding speeds as a risk factor for failure to qualify outcomes (2012-2015), Veterinary Journal. Elsevier Ltd., 236(June), pp. 37-43. 
Casella, S., Vazzana, I., Giudice, E., Fazio, F. and Piccione, G. (2015). in press. Relationship between serum cortisol levels and some physiological parameters following reining training session in horse, Animal Science Journal 87: 729-735.

Castejon-Riber, C. et al. (2017). Objectives, Principles, and Methods of Strength Training for Horses, Journal of Equine Veterinary Science. Elsevier Inc., pp. 93-103.

Clayton, H. and Science, S. H. (1992). Conditioning sport horses, Journal of Equine Veterinary Science, 12(2), pp. 121-122.

Couroucé, A., Corde, R., Valette, J.P., Cassiat, G., Hodgson, D.R., Rose, R.J. (2000). Comparison of some responses to exercise on the track and the treadmill in French Trotters: Determination of the Optimal Treadmill Incline, Vet J. 159, pp.57-63.

Evans, D. L. (2000). Exercise Training of Horses, Training and Fitness in Athletic Horses, pp. 5-7.

Fédération Equestre Internationale (2020). ENDURANCE RULES Updated 11th Edition, available at: https://inside.fei.org/sites/default/ files/FEI\%20Endurance $\% 20$ Rules $\% 20-\% 20$ 1\%20July\%202020\%20-\%2016.12.2019\%20 -\%20Clean.pdf (accessed 5 August 2020), pp. 5-75.

Ferraz, G.C., Soares, O.A.B., Foz, N.S.B., Pereira, M.C. and Queiroz- Neto, A. (2010). The workload and plasma ion concentration in a training match session of high-goal (elite) polo ponies. Equine Veterinary Journal Supplement 42: 191-195.

Fortier, J., Deley, G., Goachet, A.G. and Jullian, V. (2015). Quantification of the energy expenditure during training exercises in Standardbred trotters. Animal, 9: 793-799.

Fraipont, A., Van Erck, E., Ramery, E., Fortier, G., Lekeux, P. and Art, T. (2012). Assessing fitness in endurance horses. Canadian Veterinary Journal 53: 311-314.
Hall, M.C., Steel, J.D. and Steward, G.A. (1976). Cardiac monitoring during exercisetests in the horse. 2. Heart rate response to exercise. Aust. vet. J. 52, 1-5.

https://inside.fei.org/node/3835/, accessed 12 October 2020.

Lindner, A., Esser, M., López, R. and Bof, F. (2020) 'Relationship between resting and recovery heart rate in horses', Animals, 10(1), pp. 1-8. doi: 10.3390/ani10010120.

Linder, A., R. Signorini, L. Bredo, L.E. Arn and R. Mancini et al. (2006). Effect of conditioning catecholamine sweat electrolytes and horses 1, 2, $3 \mathrm{X}$ a week with 2 intervals of $100 \mathrm{~m}$ at near maximal speed on biochemical variables in the blood. Proceeding of the 7th International Conference on Equine Exercise Physiology, Fontainebleau, France, pp. 24-27.

Loving, Nancy S. (1997). Go the distance: the complete resource for endurance horses. Vermont, p. IX, pp. 111-116.

Mohr E., Krzywanek H., Pinkowski W. (1999). Monitoring training success using a lactate-speed relationship, Zentralbl Veterinarmed A., 46(9), pp. 565-571.

Persson, S.G.B. (1983). Evaluation of exercise toleranceandfitnessin the performance horse. In: Equine Exercise Physiology 1, Eds: D.H. Snow, S.G.B. Persson and R.J Rose, Granta Editions, Cambridge, pp 470-486.

Pringle, J., MacMillan, K., Briand, H., Stämpfli, H. (1999). Comparison of exercise variables measured during intensity of simulated training to variables at maximal effort in Standardbreds. Equine vet. J., Suppl. 30, 166169.

Robert, C., Benamou-Smith, A. and Leclerc, J. L. (2002). Use of the recovery check in long-distance endurance rides, Equine veterinary journal, Supplement 34, pp. 106-111.

Seeherman, H.J., Morris, E.A. (1990). Application of a standardised treadmill exercise test for clinical evaluation of fitness in 10 
Thoroughbred racehorses. Equine vet. J., Suppl. 9, pp. 26-34.

Siqueira, RF, Weigel, RA, Nunes, GR, Mori, CS, Fernandes, WR. (2014). Oxidative profiles of endurance horses racing different distances. Arq Bras Med Vet Zootec, pp. 61-66.

Sjodin, B., Hellsten Westing, Y., Apple, FS. (1990). Biochemical mechanisms for oxygen free radical formation during exercise, Sports Med, pp. 10-54.

Sloet van Oldruitenborgh-Oosterbaan, M. M., Wensing, Th., Breukink, H. J. (1987). Standardized Exercise Test on a Track to Evaluate Fitness and Training of Saddle Horses, Clinic for Large Animal Medicine, Yalelaan 16, 3584 CM Utrecht, The Netherlands, available at: http://www.iceep.org/pdf/ iceep2/_1129092735_001.pdf(accessed 5 August 2020), pp. 68 .

Stewart, G.A. (1981). The heart score theory in the racehorse, Australian Veterinary
Journal, vol. 57, no. 9, pp. 422-428.

Trilk, J. L., Green H. M., Lindner A., Alberghina D. (2002). A lactate-guided conditioning programme to improve endurance performance., Equine veterinary journal. Supplement, (34), pp. 122-125.

Valev, Y. (2020). Retrospektiven analiz na konnia sport, NSA PRESS, Sofia, pp. 108-128. // Вълев, Ю. (2020). Ретроспективен анализ на конния спорт, НСА ПРЕС, София, стр. 108-128. ()

Valev, Y., Nedkova-Ivanova, R. (2018). Theory and methodology of the discipline 'eventing and endurance'. Sofia, pp. 194-197.

Vermeulen, A.D. and Evans, D.L. (2006). Measurements of fitness in Thoroughbred racehorses using field studies of heart rate and velocity with a global positioning system. Equine Veterinary Journal Supplement 36: 113-117.

Corresponding author:

Ruzha Nedkova-Ivanova

Equine Sports department National Sports Academy "Vassil Levski" 21, Acad. Stefan Mladenov str. Sofia, Bulgaria

E-mail: ruja_83@yahoo.com 